\title{
EPISTEMOLOGÍA NÓMADE EN LAS CIENCIAS SOCIALES: PARA UNA RECAPITULACIÓN Y MEMORIA DE LA COMPLEJIDAD
}

\author{
Felipe Cárdenas Támara 1 \\ Universidad de La Sabana, Bogotá-Colombia
}

https://doi.org/10.33676/EMUI_nomads.55.04

\begin{abstract}
Resumen: Se señalan algunos elementos problemáticos, no resueltos aún por las ciencias sociales, que se desprenden de la noción de cultura establecida desde la mentalidad secularista dominante que tiene sus orígenes en la llustración y que ha condicionado y erosionado el reconocimiento de ontologías que esclarezcan el sentido de la actividad científica. Estas condiciones forman parte de la práctica de las ciencias sociales explicando la imposibilidad de vislumbrar de manera pragmática la vía por medio de la cual se logren integrar los conocimientos de las ciencias sociales. Dicha integración se manifestaría como una grieta de luz esperanzadora en la construcción societaria y en la generación de modelos culturales alternativos a los propuestos desde el discurso interpretativo dominante de corte efectivista.
\end{abstract}

Palabras clave: Epistemología, ciencias sociales, cultura, sociedad

\section{Epistemology nomadic in Social Sciences: For a recapitulation and memory of complexity}

Abstract: Some problematic elements are reported, not yet resolved by the social sciences that have aroused from the notion of culture established from the dominant secularist mentality that has had its origins from the Enlightenment and that have conditioned and eroded the recognition of alternative ontologies that can clarify the meaning of the scientific activity. These conditions are part of social sciences practices and explain the impossibility of catching pragmatically the way through witch to obtain integrity in the knowledge of social sciences. Such integration would manifest as hopefully as a crack of light in the construction of society and in the generation of alternative cultural models to those proposed by the dominant interpretative discourse of effectivist type.

Key words: Epistemology, social sciences, culture, society

\section{Introducción}

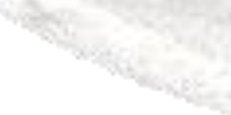

Con este documento se busca problematizar la relación epistemológica derivada de la práctica de las ciencias sociales. Es un trabajo de problematización sobre la "metodología de las ciencias sociales". La epistemología de las ciencias sociales, se puede considerar como un área del saber interesada en el análisis del conocimiento científico, en

\footnotetext{
1 Profesor Asociado de la Universidad de La Sabana, director de la maestría en Educación y del grupo de investigación Sociopolítica, cultura y ambiente. felipe.cardenas@unisabana.edu.co
} 
el estudio de los principios y valores implicados en la creación de conocimiento y en el análisis de los métodos, hipótesis y formas de interpretación de los resultados acontecidos en la labor de investigación en el campo de las ciencias humanas y sociales. La historia moderna de las ciencias sociales y sus métodos ha estado estrechamente vinculada al método de la ciencia natural. El propósito del texto es precisamente animar un planteamiento y debate teórico-práctico que ilumine, problematice, clarifique y oriente las condiciones de producción de conocimiento científico en el campo de las ciencias sociales. El trabajo busca contribuir, desde un enfoque sintético, anclado en la noción semiótica de narratividad, en el afinamiento y articulación de diferentes perspectivas de interpretación sobre el ejercicio científico en el campo de las ciencias sociales. Los problemas de orden epistemológico sobre el método en las ciencias sociales no son nuevos y han existido enormes disputas, en torno a a lo que se considera como verdad y la generación de juicios sólidos y verdaderos.

Importante tener en cuenta, como autocrítica a todo proyecto de revisión epistemológica en ciencias sociales, lo sugerido por H.C.F. Mancilla (2017) cuando afirma:

(1) la incapacidad de autocrítica; (2) la aceptación tácita de los elementos autoritarios y anacrónicos de la propia cultura porque es el legado de valores que uno mismo ha recibido ("el lugar de enunciación"); (3) el uso instrumental, demasiado evidente, del relativismo postmodernista, porque este último sirve extraordinariamente bien - con un toque de actualidad y cientificidad - a las metas de enaltecer la posición político-cultural de las naciones del Tercer Mundo y, al mismo tiempo, de diluir y hasta menospreciar los logros científicos, democráticos y organizativos de Europa occidental; (4) la preservación de una visión romántica y edulcorada acerca del propio pasado y de los regímenes autoritarios (populistas y socialistas) que prima facie parecen construir una alternativa al "capitalismo imperialista"; y (5) el cultivo de formas confusas y barrocas de exposición, junto con contenidos teóricos que a la postre se muestran como modestos o insignificantes.

El axioma y principio articular que estructura hipotéticamente el ejercicio discursivo que sigue, se apoya en la noción de complejidad, que irá emergiendo a lo largo de todo el texto. Ahora, indicar que aquello que se representa como realidad, es entendido como un tema ligado al campo de la complejidad, no significa necesariamente que los argumentos que se desarrollarán en este texto, estén inscritos en los llamados estudios sobre sistemas complejos. Si se menciona brevemente dicho enfoque paradigmático, es para señalar que incluso los apasionantes desarrollos teóricos, en los estudios sobre sistemas complejos, tienen la particularidad de excluir en sus campos de expresión y contenido, concepciones de realidad, que para algunos de sus exponentes se ubican como pertenecientes al núcleo temático de 
las humanidades, y que dadas las condiciones de globalización que vive el mundo, son campos disciplinares que para algunos pensadores se encuentran en una profunda crisis (cfr. Trigo, 2008, pp. 33-53).

Haciendo eco de la ciencia aristotélica y escolástica, se puede decir, apelando a un silogismo herético: que si el paradigma de la complejidad no incluye completamente todas las dimensiones, incluidas las del ser, se podría concluir que los denominados estudios sobre sistemas complejos, no son tan complejos como pretenden serlo y siguen reproduciendo el concepto moderno de "metodología" anclado en los postulados de la ciencia natural, que se valida con base en la experiencia y en la separación que se hace entre el objeto de conocimiento y el conocimiento del sujeto (Garza y Leyva, 2012, p. 19).

La anterior condición debe comprenderse con base en el llamado principio de inmanencia, - que cuenta con una larga tradición en el pensamiento occidental- que puede entenderse como una opción metodológica y teórica, que buscar delimitar el campo de análisis asumiendo canales de autonomía de los fenómenos estudiados con respecto a otras variables o factores (Ver Ordóñez, 2006, pp. 81-121; Orozco, 1977). El principio en mención, tiene como fin el posibilitar la organización de los objetos estudiados, aislándolos y pensándolos como autónomos en determinados momentos del proceso de análisis e investigación metodológico; se busca la objetividad y la verdad, vinculando teoría y experiencia, mediante procesos de observación controlados y experimentales que se dirijan hacia a la búsqueda de leyes universales. Para Orozco (1997) el llamado inmanentismo gnoseológico, se origina en los tiempos modernos. Sus propulsores más reconocidos fueron Galileo y Descartes. Ellos consideraron que como criterio de excelencia, la metodología de investigación debería de estar condicionada a la observación controlada sujeta a las matemáticas. Esta línea de pensamiento, con sus desarrollos particulares, se hará presente en los sistemas de Hegel, Berkeley y Marx y marcará las representaciones científicas de la antropología y la sociología en sus primeros desarrollos a mediados del siglo XIX. El criterio procedimental para alcanzar la verdad se vinculará a la noción de empiricidad, que establecerá las bases de los primeros criterios positivistas para definir la verdad, que se entiende según Auguste Comte, como ligada al método y a la prueba empírica. Recuerdan Garza y Leyva (2012) que a partir del final del siglo XIX apareció:

...la llamada disputa por los métodos, en el marco de la discusión Geisteswissenchaften (ciencias del espíritu)/Naturwissenchaften (ciencias de la naturaleza) del neokantismo (Wildelband y Rickert), del historicismo $-y$, más tarde, de la naciente hermeneutica en un autor como Dilthey - por un lado, y del empirismo (Mill) —al lado del naciente positivismo (Comte) - por el otro (p. 20). 
El discurso científico dominante de la modernidad y su racionalidad, la denomina Ambrosio Velasco como "monismo naturalista" (Velasco, 2012, p.199). Esta concepción, nacida en el seno de las ciencias naturales, y adoptada - podría decirse que acríticamente por las ciencias sociales-, estableció el punto de quiebre de la modernidad con el pensamiento escolástico, generando la oposición representativa entre inmanencia/trascendencia que será fundamental para entender la distinción entre ciencias duras/ciencias blandas, entre humanidades y ciencias sociales (Paulucci, 2014, pp. 93-122) y en la separación de la ciencia de los postulados metafísicos y teológicos. Dicho proceso, generó un vaciamiento de las capacidades humanas para entender la estructura de realidad. En ese orden de ideas se constata una crisis metafisica, que incluso puede entenderse como elemento explicativo de primer orden en los llamados problemas ambientales contemporáneos y en la pobreza de contenidos educativos con las que hoy los sistemas escolares, incluidos los universitarios, pretenden formar a los ciudadanos, específicamente en unas "competencias" que basicamente los hace funcionales al aparato productivo del sistema neoliberal.

La anterior aseveración se puede constatar como presente en las ideas que se expresan en lecturas y textos recientes escritos por importantes representantes de los enfoques "duros" en ciencias sociales. Por ejemplo, J. Stephen Lansing y Sean Downey en su trabajo titulado Complejidad y antropología (2011, p. 569), situán la historia de esta disciplina como constituida por un campo de estudios que ellos denominan "humanísticos" y otro campo de estudios "científicos". Afirman ellos que los estudios humanísticos, tienden a ser dudosos (dubious) sobre la aplicación de métodos científicos en los sujetos antropológicos. Estos científicos sociales optan por estudiar los enfoques Naturwissenschaften o científicos, como expresión relevante de la antropología en sus aportes a trabajos sobre sistemas complejos. Para Lansing y Downey, los estudios que ellos denominan científicos son de orden popperianos o tienen la creencia en la unidad del método científico. Es importante señalar que estos autores en su infento por vincular la antropología con los estudios sobre sistemas complejos, reconocen que este naciente enfoque o campo de estudio, complejiza aún más el abordaje epistemológico o la caracterización de la historia disciplinar de las ciencias sociales.

Conviene notar, que otras perspectivas en el campo de las ciencias sociales reclaman un retorno y énfasis humanístico. Por ejemplo, los trabajos de Andrew Sayer (2004) referidos a la sociología, sugieren la importancia de recuperar, como objetos de estudio, la dimensión moral y ética en las investigaciones contemporáneas. Según este autor, estos temas han sido desplazados por el énfasis que se les ha otorgado a los estudios sobre hábito, discurso e interés. Volviendo al tema de los estudios sobre sistemas complejos y al marco definitorio que Lansing y 
Downey (2011, p. 569) hacen de la noción de "complejidad, ellos la definen, en términos generales, como el estudio de procesos no lineales. Se tiene que destacar, que esta breve definición, no es para nada inocua; su concepción básica, denotativamente matemática, sigue reproduciendo las raíces del viejo debate que Dilthey (1910) realizará en sus críticas a los enfoques evolucionistas de Auguste Comte y de Herbert Spencer y que en el fondo tienen continuidad con un viejo debate que viene desde el renacimiento y que René Descartes en sus obras Reglas para la dirección del espíritu (1628) y Discursos sobre el método (1637) planteara en clara oposición a los razonamientos de la ciencia medieval, cuya estructura de indagación de lo real se apoyaba fundamentalmente en la silogística aristotélica. Según Thomas Kuhn (citado en Garza y Leyva, 2012, p. 19), la fundamentación de la verdad basada en la idea de la prueba empírica cuantitativa se impondrá solo hasta mediados del siglo XIX. La validación final del conocimiento científico, en la naciente sociología del siglo XIX estará condicionada en su máximo rigor por la prueba empírica cuantitativa. Como respuesta a estas tendencias cuantitativas se originó todo un movimiento científico a finales del siglo XIX, que respondió a la pretendida hegemonía de las ciencias naturales en el ámbito de lo social. La llamada "disputa por los métodos" se enmarcó en el desarrollo de enfoques que se han caracterizado como ligados a las orientaciones de las "ciencias del espíritu" o Geisteswissenschaften. En el campo de estudios de las "ciencias del espíritu", se hace relevante la referencia a la realidad histórica y cultural, que a su vez se entiende como configurada por individualidades que llaman a la comprensión de los fenómenos humanos en toda su particularidad (Dilthey, 1980; Gadamer, 1993).

La obra de Wilhelm Dilthey (1833-1911) será fundamental para la génesis moderna de los estudios hermenéuticos, entre los cuales se destaca Hans-Georg Gadamer (1990-2002) como uno de sus más emblemáticos representantes. Como efecto de esa realidad histórica, tal como señalara M.F. Sciacca (1960, p. 200), la ciencia dominante de carácter empírico y apoyada fundamentalmente en el ideal científico de la ciencia natural, extrapolará sus resultados de laboratorio y extenderá su horizonte a toda la experiencia, sobre la base de un empirismo riguroso, exigente y absoluto, desarrollado sobre las posiciones del empirismo de Locke y de Hume. Las consecuencias gnoseológicas y epistemológicas para la ciencia se expresan en palabras de Sciacca (1960, p. 200) así:

Por lo tanto, la nueva ciencia, a través de la absolutización y de la <<extrapolación>> del principio empirista, resuelve la <<substancia >> espiritual y material en la <<experiencia pura>> y, por consiguiente, niega que haya una substancia (cualquiera que sea) más allá del fenómeno: por una parte, se reduce toda experiencia a <<sensaciones>>, y, por otra, la sensación es ella misma todo lo real, su substancialidad. Esto es tanto como decir: no hay substancias, ni ser, ni esencia, palabras <<sin sentido>>, míticas, <<inverificables >>. 
En el fondo, tal como señala Sciacca, se constata que en la herencia galileana-cartesiana-newtoniana, se está ante una profunda disolución del ser y de desintegración del pensamiento. Una auténtica renovación de la ciencia, tendría que acometer la tarea de revisión de los supuestos racionalistas que fijan como límite de la experiencia humana la experiencia sensible.

\section{La práctica científica, inmersa en estructuras narrativas.}

La metáfora y realidad de lo narrativo, se impone como constante en cualquier sistema de representación de la realidad. La noción de narratividad es es útil para emprender un análisis de corte epistemológico riguroso y con posibilidades diversas y plurales demarcaciones tipológicas (Durand, 1982; Harris, 1968; Sorokin, 1969). No se puede renunciar a entender que la labor de generación de conocimiento debe de estar orientada, en tanto intencionalidad, por el principio de la búsqueda de la verdad. Condición que comparten las ciencias sociales, con la filosofía y la teología.

Cabe sugerir la importancia de reconocer como prioritario la apropiación del principio de la complejidad como criterio general para contextualizar el ejercicio científico de las ciencias sociales. Conforme a esto, simplemente señalar cómo una "simple" conversación entre dos personas o un "sencillo" análisis gramatical de un texto, como lo demuestra la lingüística y la semiótica, están constituidos por un haz de relaciones extremadamente intrincadas y que son objeto de análisis, discusión y de descubrimientos permanentes hasta la fecha (ver Peirce, 1973; Saussure, 1994; Sorokin, 1969; Elias, 2006; Courtés, 1997). Esta red de relaciones y extensiones, llevada al análisis de los hechos cotidianos, puede pasar desapercibida o ser ignorada por los propios científicos sociales, o ser descrita simplemente de manera superficial. Algunos de los componentes o dimensiones que deben considerarse como parte de un modelo de análisis heurístico en el campo de las ciencias sociales debería estar marcado por la observación y consideración de los siguientes procesos: i) actos de la conciencia, (hoy ignorados por parte de los sistemas complejos) ii) lengua/lenguaje/habla iii) realidad sociocultural y iv) realidad material (territorio, ecosistemas, ambientes construidos, paisajes culturales), establecen un conjunto de trazos vinculantes y relacionales desde los cuales tiene que partir una reflexión epistemológica-teórica en el campo de las ciencias sociales.

En ese orden de ideas, se tiene además, que la realidad humana es más que lenguaje; por importante que sea el plano lingüístico, la condición "real de la realidad" humana expresa otras especificidades cognoscibles de orden extrasomáticas, que desbordan la corporalidad, en campos y dimensiones que transitan en las topografías imaginarias, oníricas, representacionales y reales de los planos arquitectónicos que constituyen el mundo de lo humano (Por ejemplo la cultura material de 
una sociedad, la cultura escolar de un colegio). Este tránsito puede ser conocido desde el sentido común, así como por medio del despliegue de dimensiones teológicas/religiosas, filosóficas, y científicas, sobre las cuales el científico social pretende conocer la realidad, ya sea desde visiones reduccionistas, que excluyen componentes de la misma, en aras de una funcionalidad operativa de sus instrumentos de observación; o desde modelos heurísticos que buscan comprender la realidad de los procesos humanos incorporando visiones integradoras y complementarias de los fenómenos sociales, que de todas maneras siempre brindarán lecturas parciales de los hechos que se observan.

Se tiene que ser cuidadoso sobre el uso equívoco de la noción de ciencia por parte de los propios científicos sociales. Dada la complejidad del campo estudiado, es usual el encontrarse con datos pretendidamente científicos, que en el fondo son la expresión de nociones pseudocientíficas, que incluso están amparados en modelos estadísticos y matemáticos que tienen serios errores de medición, pero que son presentados como resultados de conocimiento verdadero y válido sobre la realidad (Scheff, 2011, p. 264; Sorokin, 1957). Lo más catastrófico, es que los científicos sociales, hijos putativos de los métodos de las ciencias naturales, en algunas tendencias, pretenden medir la realidad como si la sociedad humana fuera simplemente un hecho o un evento, localizado en un mundo exterior que puede ser simplemente estudiado como si fuera un objeto físico o biológico exclusivamente (Voegelin, 1952). Los mismos científicos sociales se han exigido a sí mismos, una ciencia social que esté en capacidad de proporcionar un conjunto de leyes, quasi-leyes o generalizaciones con "fuerte poder predictivo" (MacIntyre, 2001, p.116). Pero la realidad es que las capacidades predictivas del científico social son relativamente inexistentes, condición que es aplicable a economistas, administradores y demógrafos.

\section{Referentes de sentido.}

La exposición que sigue busca delimitar sintéticamente la enorme frontera investigativa de carácter teórico, con base en la afirmación de Karl-Otto Apel (1997, p. 21) que menciona cómo en la llamada sociedad industrial, las filosofías que subyacen a los principales planteamientos epistemológicos son el marxismo, el existencialismo y el pragmatismo. En un diálogo plural, que no agota la pluralidad de posibilidades analíticas, parece que el camino unificador/complementario entre una y otra ciencia y destacando la particularidad de las ciencias humanas, en tanto su campo de estudio, estaría dado por la vinculación fructífera a la <<máxima pragmática>> de Charles Sanders Peirce y que para el caso de las ciencias sociales, debería acentuarse más, dada su condición de disciplinas ligadas, a lo que se puede definir como ciencias del sentido. 
Es preciso recordar que la <<máxima pragmática >> está orientada a un proceso de clarificación de las ideas y de la crítica de sentido, tarea y propósito de la que ningún científico está exento. En este paradigma, sus componentes o formas de enunciación lógica, orientados hacia el fortalecimiento y diálogo de la comunidad científica, están encauzados hacia el desenmascaramiento, como señala Karl-Otto Apel, de toda formulación de problemas ontológicos carentes de sentido (1997, p. 33). La <<máxima pragmática>> de inspiración peirceana, tiene un fuerte sentido crítico que advierte de los riesgos de los eclecticismos y previene contra los juegos de lenguaje pragmáticamente vacíos (Apel, 1997, p. 33).

Para comprender el vasto universo temático de las significaciones producidas por las ciencias sociales, se tendrá en cuenta lo que Alasdair Maclntyre (2001) hipotéticamente sugiere cuando afirma que las argumentaciones de nuestra época están marcadas por una clase de afirmaciones que se reproducen en el debate moral y científico, a la luz de enunciados fragmentarios que se contraponen entre sí, como premisas sobre la realidad. Esa base argumentativa constituye los cimientos del desacuerdo moral contemporáneo que se expresa como la incapacidad comunicativa dada por la existencia de diversas premisas conceptualmente inconmensurables. Los orígenes históricos de este aparente pluralismo epistemológico que no logra comunicarse entre sí, son ubicados por Maclntyre (2001) en el concepto de justicia, por un lado y en lo que se entiende por modernidad, por el otro. El concepto de justicia deviene de las virtudes aristotélicas, cuyo componente sociológico se tiene que entender como expresión del sentido de vida existente en sociedades premodernas. Por su parte, lo definido como modernidad, incorpora otro esquema y estructura de significación y orden moral que puede ser identificado como proveniente de los aportes de Maquiavelo, Hobbes, Marx y Weber y que rompieron de manera general con toda referencia a la existencia de primeros principios, de la indagación sobre la noción o categoría del ser y sobre el propio sentido de la existencia. Un preciso análisis de las proposiciones utilizadas, siguiendo lo señalado por Maclntyre (2001), afirma que la doctrina emotivista entiende que los juicios morales no son nada más que expresiones de preferencias o sentimientos; es decir, significados proposicionales desvinculados de un eje valorativo ligado a esquemas morales y éticos, que, a la luz de la modernidad, pasaron a entenderse como sujetos del relativismo moral que opera en la teoría de la significación de la doctrina emotivista.

En dicho contexto, se hace axial el diálogo entre las ciencias sociales, pues está demostrado, que la complejidad de las entidades, fenómenos - realidades estudiadas, implica un esfuerzo teórico-práctico permanente de integración de diversos planos y procesos mentales, materiales, existenciales y ónticos tanto del investigador-interprete, como de los grupos; tanto de las configuraciones socioculturales, como 
de sus territorios-interpretantes con las que trabaja el investigador social (Cárdenas, 2016). No es una tarea sencilla, ya que habría que buscar que los modelos analíticos, deductivos o inductivos en el plano teórico, se articularan a la luz de la teoría semiótica, de una teoría del orden, la historia, como de los procesos cognitivos que operan en el campo de los actos de la conciencia humana en la que operan las configuraciones socioculturales. A manera de ejemplo, un problema de investigación $X, Y, Z$, por ejemplo, la historia o sociología de un pueblo, con toda seguridad ganará en potencia interpretativa, si los métodos de la economía, sociología, geografía, historia, psicología y la antropología se conjugan creativamente (Kertzer, 2009).

Conviene notar, que la anterior exigencia, establece así mismo, una de las grandes debilidades de las ciencias sociales, la cual tiene que ver con la incomunicación teórica entre sus disciplinas, lo que impide un acople de sentidos que permita la generación de conocimiento dentro de la unidad paradójica de las diferencias existentes, tanto en el sistema social de las sociedades contemporáneas, como al interior de las comunidades científicas (Luhmann, 1998; Latour, 2011). Un ejemplo, que expresa con claridad como la incomunicación afecta la comprensión de los resultados de investigación operados en la ciencia social es el de los estudios sobre el suicidio. En sus trabajos, Thomas Scheff (2011) afirma que es una calamidad que las ciencias sociales, ignoren aún las causas del suicidio. Según él, la situación es grave, pues es uno los fenómenos más estudiados; en su opinión las teorías no han logrado integrarse para comprender las causas del mismo. Scheff, cuyo correlato científico es el método de las ciencias naturales, se ensaña contra las ciencias sociales por la falta de explicaciones causales o por la presencia de estudios rigurosos. Para este autor, de nada valen los estudios sobre un tema muy trabajado, y que arrancaron con la obra pionera de Emilio Durkheim ([1897] 2004), si el rigor matemático o estadístico está mal desarrollado. Admitiendo con el autor en mención, que no es fiable una mala matematización de la realidad; lo que él olvida en su crítica al cientismo en las ciencias sociales, es que hay fenómenos que no se pueden explicar sólo con base en un modelo causal de orden estadístico. Siguiendo con el ejemplo, el achaque positivista culparía a la sociología moderna por carecer aún de un modelo causal explicativo sobre el suicidio (Sheff, 2011, p. 266).

\section{Ascendencias putativas en mundos reformados, contra-reformados y desfigurados}

Las complejas formas culturales y civilizatorias entroncadas en la matriz occidental fueron determinantes en la constitución de las narrativas de referencia del proyecto llustrado y de su visión universal. Los saberes llustrados, que mantuvieron continuidad con los bosquejos conceptuales derivados del mundo greco-romano, el cristianismo 
patrístico y la escolástica, fueron constitutivos de los marcos civilizatorios derivados de la idea ilustrada de ser humano. Estos modelos intelectuales propiciaron, acompañaron y justificaron las principales aventuras coloniales e imperiales del continente europeo, que con base en los postulados del libre comercio, la ganancia, la rentabilidad de la tierra, la propiedad privada, la noción de apertura al mundo, el desencantamiento de la realidad y la idea de familia monógama, se abrogó el derecho a la explotación de los pueblos salvajes y barbaros, a los que se tachó de no tener historia, ni ciencia (Wolf, 2005).

En la construcción de las ciencias sociales han intervenido una gran variedad de enfoques teóricos, metodológicos e hipótesis de trabajo, así como han confluido condiciones sociales e históricas estructurantes. En el plano histórico, y en el contexto de la Revolución francesa y de la reforma protestante, los aportes de la filosofía continental (Francia, Alemania) y la filosofía anglosajona fueron determinantes en el surgimiento de los enfoques de las ciencias sociales (Hottois, 1997). El descubrimiento de América, debe recordarse, propició muchos de los imaginarios (el buen salvaje) que condicionaron el surgimiento de la reflexión moderna sobre el estado y de la otredad, como principio fundamento de lo más luminoso del pensamiento antropológico de la era ilustrada.

Consecuentemente, el lugar del ser humano en la realidad y las formas de entender su naturaleza, se han modificado como resultado de las diversas perspectivas temáticas que abordaron los principales exponentes de la llustración. La llustración, como "estado de tutela", debe entenderse como un proceso histórico que modificó las relaciones prexistentes de voluntad, autoridad y "uso de la razón" (Kant citado por Foucault, 1995). El resultado fue que la visión de hombre, naturaleza y sociedad se transformó paulatina y radicalmente.

El logos occidental, que mantiene continuidades catafáticas (de afirmación), en muchos casos no reconocidas explícita o conscientemente con ese universo mediterráneo, ha sufrido evoluciones o erosiones en las pautas operativas de sus esquemas mentales. Como resultado del cambio de régimen de producción discursivo establecido desde la llustración, en un proceso de desencantamiento del mundo, el lugar de Dios se desplazó del centro a la periferia o incluso fuera del sistema explicativo. La Reforma protestante, particúlarmente los filósofos morales reformados, asumieron la base científica de la existencia de Dios y desde su omnipotencia ya fijada, se dedicaron a explicar el funcionamiento de la divinidad en los hechos del mundo (Monares, 2003). La perspectiva providencial-legalista, finalmente terminó generando un ambiente para la indagación científica de la realidad a partir de una indagación sobre leyes del comportamiento, la regularidad de ciertos sucesos (leyes) y la posibilidad de la predictibilidad. Los impactos de la concepción providencialista en disciplinas como la economía fueron inmensos. Las obras de John Locke 
y Adam Smith, apoyados en los postulados calvinistas, dejaron sus influjos hasta nuestros días al fijar leyes cuasi-teológicas que explican las formas de generación de riqueza en sistemas guiados por mercados autónomos que funcionan con base en la mano invisible y leyes que en teoría deben de proporcionar elevados niveles de armonía, eso sí sujetos al dios-estado. Los economistas han asumido de forma explícita y orgullosa el modelo de la física, dando paso a la matematización de la disciplina y dejando de lado a la economía política, y sus sentidos sobre la generación de riqueza. El presupuesto del enfoque cuantitativo, dominante en la política pública de todas las naciones del mundo, parte del axioma que afirma que la conducta humana está predeterminada. Por lo tanto, se asume que los comportamientos sociales en el área productivo-comercial se rigen por leyes $y$, por tanto, son predecibles y expresables a través de números y fórmulas.

Los postulados económicos en mención, anclados sobre presupuestos religiosos, tuvieron un efecto radical sobre el funcionamiento del mundo. Hace referencia a ello, W. Pannenberg (1993), cuando afirma que, para la antropología moderna, una vez vaciada de fe, la ciencia del hombre ya no se entiende partiendo de Dios, como lo hacía de manera concreta la tradición cristiana. La ruptura en mención es una de las características de la modernidad y se refiere a un alejamiento de la tradición religiosa, particularmente la referida al dominio de la Iglesia Católica Romana, que, a su vez, según la teología bizantina, después del cisma del año 1054 se había separado de la auténtica Iglesia de Cristo. Los padres de la Reforma, Calvino y Lutero, establecieron las bases para la autoconciencia y autoperfeccionamiento del hombre en una dinámica inflacionaria que posibilitara el campo de los sectarismos/faccionalismos/pluralismos, en el esquema de la salvación del hombre o en el mercado de las almas que rige hoy los refinados esquemas de explotación del neoliberalismo contemporáneo.

En efecto, el hombre moderno pasó a entenderse como una expresión histórico-social y como parte de la naturaleza, que a su vez debía de ser conquistada por el engranaje científico-técnico que el mundo industrializado en el siglo XIX empezó a desarrollar. Estas rupturas han sido paulatinas y tienen que ver con el vacío de contenidos existenciales que no forman parte de las preocupaciones analíticas de los modelos histórico-sociales. A estos, poco les importa que pasa en el corazón de los hombres. En esencia, está es la tragedia metafísica de occidente y de la cual las ciencias sociales son una de sus exponentes.

Debe recordarse que, en el contexto de la antropología medieval cristiana, el hombre era considerado como imagen de Dios. Ya en el renacimiento, los filósofos morales escoceses comenzaron a entender la naturaleza humana desde ángulos que no eran necesariamente religiosos o teológicos (Gordan, 1995, p. 133). El hombre era visto y definido como uno más entre las especies. Se adoptó así, en cierto sentido, la perspectiva estoica que entendía al hombre en el marco del 
orden del cosmos, como microcosmos en correspondencia con el macrocosmos del universo físico (Pannenberg, 1993). Lo anterior no se puede generalizar, ya que algunos filósofos morales escocés, mantuvieron dentro de su lenguaje, las nociones de "Providencia" y "Deidad" (Gordan, 1995, p. 133).

Lo interesante de este debate para las ciencias sociales, es que incluso aún hoy día, la discusión sobre el lugar señero del hombre sigue dominando la aludida cuestión. ¿Qué es lo diferencialmente humano? Para la tradición metafísica cristiana el fundamento del hombre se derivaba del concepto de alma espiritual inmortal, atributo exclusivo del él. En ese orden de ideas, la noción de imago dei se podría considerar como el símbolo (revelado) más importante de la filosofía política cristiana y desde la cual se configuró Europa, que más que un continente es una idea anclada en formas institucionales grecoromanas y experiencias de orden semitas. El anterior sentido cristiano y bíblico, fue desafiado por los intelectuales "modernos", que manejaban un enfoque teológico denominado "religión natural" o "deísmo". La consecuencia de dicha orientación fue la de darle un giro distinto, al desviar la atención del estudio de los textos sagrados y "orientarla hacia el estudio empírico de la obra de Dios en la naturaleza" (Gordan, 1995).

Como lo recuerda Pannenberg (1993), el giro decisivo en la forma contemporánea de las ciencias sociales, trabaja bajo el supuesto metódico de la continuidad entre el hombre y el animal. Los precursores a estos modos de consideración se encuentran en los siglos XVIII y XIX, especial lugar merece Herder y Nietzsche. Pero la ruptura central tuvo lugar en el momento en que la psicología dejó de buscar el acceso a lo anímico valiéndose de la introspección y recurrió a la conducta externa. Este proceso sucedió a principios del siglo XX, por un lado, en el conductismo americano y por otro, en la investigación biológica de la conducta.

Este posicionamiento histórico-social aparentemente demolió o viene destruyendo con todo intento definitorio de índole sustancialista y/o esencialista, abriendo/erosionado las posibilidades del conócimiento científico sobre lo humano, de sus experiencias y del carácter de su movimiento desde un fuerte componente de orden empírico, que como se ha mencionado eliminó la pregunta ontológica por el ser y por el sentido de la existencia, por lo menos en los marcos hegemónicos de las principales corrientes dominantes de la ciencia. En la actualidad, la labor científica se orienta por el sentido de la diferencia, que viene a ser el eje articulador del discurso científico en las antropologías estructuralistas y postestructuralistas (Viveiros, 2010, p. 217). No existe una clara perspectiva que vincule las semejanzas y diferencias culturales con una ontología de la relación. Las esencias platónicas y la región de las ideas ya no serán de interés, pues la atención se enfoca hacia el campo de los procesos transformativos y el estudio de las dinámicas intersocietarias en clave perspectivista y en un horizonte culturalista que 
deifica al nativo de hoy como si fuera él, la figura incontaminada del buen salvaje de ayer.

\section{Algunas particularidades humanas: giro lingüístico o ontológico}

Como ser histórico-social, el ser humano está situado en un contexto marcado por la condición del lenguaje. Y es a través de la palabra que el hombre se interpela y actúa en lo cotidiano y en la vida científica. Una peculiaridad biológica en el hombre es su capacidad para el lenguaje y la razón. Esta condición reclama un relacionamiento de las ciencias sociales, específicamente las ciencias del lenguaje, con la fisiología y la biología. Pero esa misma condición es un sello particular de la cultura humana que tiene la capacidad para el habla, el discurso $y$ el metadiscurso desde un razonar basado en funciones derivadas y condicionadas en diversas racionalidades, ontologías y experiencias de orden.

El lenguaje y la razón están en estrecha relación con la formación de la cultura, de sus utopías, proyectos políticos y movilizaciones (Eisenstadt, 2007; Bauman, 2002; Apel, 1997). Es mediante la cultura, anclada en el lenguaje, que el ser humano genera paisajes culturales, ya sea reales, o utópicos, y que se recrean en la memoria, en la topología de la cultura, incorporándose a la naturaleza biofísica, entendida como ambiente en el orden de su mundo. El lenguaje es fundamental para todos los dominios y actividades humanas. Un examen sobre la vida cultural de los hombres tiene que destacar y profundizar de modo especial en el lenguaje, además de abordar los signos somáticos y extrasomáticos que acompañan el deambular histórico del ser humano. El lenguaje de cada cultura humana, en el horizonte del relativismo lingüístico, expresa la visión particular de mundo de esa cultura y en ese sentido, abre y cierra posibilidades para captar, construir y sentir experiencias de orden (Voegelin, 1952).

Como hijas de la historia y de fuertes confrontaciones religiosas (Reforma y contra-reforma), las ciencias sociales, han mimetizado o enmascarado alguno de las categorías teóricas de raíz religiosa, secularizándolas o simplemente pensando que operan desde enunciados libres de connotaciones religiosas. Lo anterior no afirma completamente, que la intencionalidad teológica de cuño cristiano haya desaparecido, o que estas finalmente estén al margen de visiones doctrinales que proyectan de manera camuflada las concepciones iconoclastas del protestantismo o los regímenes mentales del racionalismo monárquico- papal de la Iglesia romana.

De modo que, la idea ilustrada de cultura abrió paso a la autoconciencia del individuo y a las relaciones de este con las dimensiones socioculturales (Mendelssohn, 2014). La investigación en ciencias sociales establece e identifica el peso de las determinaciones materiales en las relaciones sociales de la vida del individuo humano en 
procesos donde hay que estudiar factores ligados a la cooperación, el conflicto y la violencia (Marx, 2012). En ese sentido la violencia sacrificial es parte de la trama de toda configuración cultural (Girard, 1986). Se puede decir que dicha trama está incluida la empresa científica, si se entiende que toda forma cultural es en el fondo un código arbitrario, constituido por sentidos heredados, normas y valores, que en algunas configuraciones culturales se transforman aparentemente con lentitudes generacionales o milenarias.

En líneas generales, uno de los grandes aportes de las ciencias sociales, es el de haber contribuido a destacar la importancia de los fundamentos de la cultura en los actos del habla y en la misma determinación del lenguaje humano como sistema de signos y de símbolos. El reconocimiento de la importancia de la vida de los signos y símbolos, configurados como discursos sociales, políticos, administrativos y científicos es uno de los grandes aportes de las ciencias sociales. Lo afirma $\mathrm{C}$. Peirce de manera elocuente y está en la base de una larga, rica y diversa tradición de estudios en el campo de las ciencias humanas: "... los símbolos son la urdimbre y la trama de toda investigación y de todo pensamiento." (Peirce, 1973; Bachelard, 1986; Coomaraswany, 1980; Corbin, 1996; Durand, 1982; Eliade, 1989; Guenón, 1988, Heiddeger, 1990).

Si la noción de cultura, anclada en cadenas de significación que atraviesan toda la realidad, es tan importante, se debería contar con un(os) modelo(s) teórico(s) que diera(n) respuesta a un entendimiento y comprensión más cabal sobre la dinámica de las configuraciones culturales en sus diversas escalas (familia, empresa, nación, tribu, organización, institución). Pero la realidad es que la categoría de cultura aún no tiene una respuesta plenamente satisfactoria en el campo de las ciencias sociales, dada la falta de formación sintáctica y lógica que se le brinda a los científicos sociales. Es decir, se tiene una larga tradición de estudios que destacan la importancia de la lectura de los contextos culturales, sin embargo, las ciencias de la cultura o ciencias sociales, no brindan todavía respuestas plenamente satisfactorias sobre la episteme de la cultura, que como se afirma, debe precisar su lógica comprensiva sobre la lengua (lingüística), las cadenas de significación (semiótica) y sobre el universo sociocultural (antropología, historia y sociología).

El conocimiento, en este contexto, se toma como una creencia que es legitimada y compartida socialmente. Las creencias tienen la función de orientar, comprender, explicar, transformar, recrear y dan identidad y pautas de acción sobre la realidad; permiten la comunicación en procesos intersubjetivos mediados por los valores y significados que otorga el entorno cultural en que se vive. Diversas escuelas comparten esta concepción (Boudon y Bourricaud, 1982). Comunicar las creencias se logra por diversos medios o vehículos, uno de ellos es el lenguaje, que puede ser escrito o verbal, y que por preciso que sea, nunca mantiene una relación inequívoca con la realidad, dada la dinámica e 
importancia del pensamiento simbólico, cuya realidad es estructura estructurante de todos los hechos humanos (Bourdieu y Wacquant, 2008; Cassirer, 1983; Pannenberg, 1993; Lévi-Strauss, 2006; Barthes, 1993; Geertz, 1973). Por esa razón la distinción de T. Parsons entre sistema cultural y sistema social sigue siendo importante. La sociedad, en tanto interacción entre grupos, para poder constituirse, necesita del orden axiológico del sistema cultural (Parsons, 1976). Es cierto también, que cierto sentido supraindividual, bajo las ideas de E. Durkheim (1964), revela cierta expresión de la superioridad de la propia sociedad sobre sus miembros singulares. La diada cultura-sociedad, introduce otro elemento indispensable para la comprensión de la cultura; ese tercer plano, distinto del individuo y distinto de la sociedad es el del mito. Esa nada despréciable dimensión de la realidad, es un campo temático de hondo calado, que refiere atributos teándricos (lógicas metacomplejas) en el universo de los hombres, los animales, las plantas y los dioses. En efecto, la mayor parte de las culturas humanas en su autocomprensión de sí mismas, cuentan con un relato mítico que tiene la función de informar el/sobre el (des) orden social, así como del cosmos natural.

La conciencia individual, así como la conciencia o praxis religiosa, se refieren a dicha dimensión y encuentran en ella las gramáticas de sentido y postulados existenciales necesarios precategoriales (la naturaleza) o categoriales (filosofía, religión, teología, ciencia) que le otorgan a la sociedad su base diferenciadora para comprenderse en el mundo. El nivel del mito, o la capacidad mitologizante en el ser humano, fue uno de los elementos que la llustración pensó haber derribado, en una actitud iconoclasta que se mantiene hasta el día de hoy y que se expresa en el odio militante hacia cualquier tipo de manifestación pública de lenguajes religiosos o presencia de iconos sagrados en las arenas políticas de ciertos movimientos sociales, instituciones académicas, partidos políticos, Estados laicos o totalitarios, como en muchos centros de investigación académica.

La capacidad mitologizante en mención no es ajena a la empresa científica y ha formado parte de las religiones políticas que dominaron el paisaje de países como la Unión Soviética, cuando estuvieron sometidos a la dictadura del partido bolchevique ruso. En este orden de ideas, los datos empíricos comprueban la importancia incuestionable del hecho religioso en la configuración de la humanidad (Rappaport, 2001). Lo cierto es que la pregunta sobre la existencia de Dios o de entidades espirituales/religiosas han sido respondidas con el mayor rigor y profundidad en el campo de la teología, fenomenología religiosa, historia de las religiones y la metafísica (Bulgakov, 2012; Lossky, 1982).

Temas como el del amor, la maldad, odio, intriga, sentimientos, miedos y otras constantes antropológicas, que han sido objeto de desarrollo en los universos míticos, literarios o religiosos, en muchos casos han sido ignorados por las ciencias sociales en el juego por caracterizar los comportamientos y costumbres (hechos sociales) de pueblos exóticos o 
cercanos desde modelos analíticos que los entienden como si sus comportamientos humanos se pudieran leer con los mismos lentes como se lee el funcionamiento de una colmena de abejas. La impronta de esta mentalidad la marcó fuertemente Emilio Durkheim, condicionando el imaginario colectivo de las cosmovisiones científicas que reducen todo a la dinámica de los "hechos sociales"; este co-relato ha sido determinante en el desarrollo o estancamiento de los enfoques objetivos de las teorías de la cultura, la sociedad y de los modelos lingüísticos. El método en mención, paradójicamente rico en tanto descubridor de la importancia del papel simbólico de lo social, ignora la fuerza estructurante de lo simbólico específicamente en la referencia al papel primordial de los mitologemas en la historia humana y de la capacidad de libertad tienen los hombres, como movimientos sociales para definir y demarcar su propia historia.

Si la actividad mitologizante es una constante en el hombre y sus configuraciones culturales. Se desprende de ello, que el mito tiene la fuerza de formular y estructurar la realidad, de ordenar una sociedad, procurando establecer las bases de correspondencia con un orden cósmico, que puede ser tanto proyección del hombre como proyección de una entidad o entidades que remiten a ontologías aproyectivas de la dinámica psicológica de los seres humanos. En esos planos, siempre el referente mítico y sus narrativas encontrarán interesante reflexionar y aprender sobre el lugar que ocupa la ofrenda de Caín o de Abel, como las narrativas míticas de todos los pueblos. El mito funda la realidad y define incluso la ontología de la ciencia y sus tramas discursivas representadas en los discursos y relatos sobre el progreso, el desarrollo y la evolución de la sociedad humana.

La complejidad de la trama mencionada, la expone Pannenberg (1993, pp. 423-427) al preguntarse: ¿cómo explicar que el estilo vital de una cultura pueda entrar en tensión y a veces en abierta oposición con la religión oficial de esa cultura, como sucedió en el Renacimiento y la llustración europea? Es decir, se destaca que la religión y la cultura hacen parte del mismo sustrato, pero pueden también estar diferenciadas y funcionar autónomamente y con relativa independencia de ciertas esferas profanas de la vida respecto de la tradición y la praxis mítica y religiosa, tal como argumentara $B$. Malinowski, y en contra de la perspectiva de E. Durkheim y L. Lévy-Bruhl. Entonces no necesariamente mito y religión constituyen la unidad de una cultura, o deben tomarse como significantes equivalentes. Por lo tanto, lo que se puede interpretar como una de las constantes humanas más fundantes, remite a la capacidad mitologizante, si se entiende por ello, como la capacidad que tiene el ser humano de proyectar mundos reales y no-reales, en todos los planos de la realidad.

En lo relativo a culturas más complejas, estas se caracterizan precisamente por contar con mayores procesos de diferenciación y autonomía de sus instituciones. La religión, incluso antes del 
Renacimiento y la llustración, y en contra de la opinión generalizada no era el ámbito de vida dominante en diversas culturas del mundo. El mito, la cultura y la religión cambian, se transforman y se renuevan, presentándose siempre de manera nueva o renovada ante la comunidad de fieles. Incluso una actitud o conducta pretendidamente a-religiosa puede estar funcionando desde connotaciones mitológicas o religiosas.

Entre tanto el prejuicio secularista moderno tampoco puede subestimar los contenidos semióticos que se establecen en el discurso o relato mítico-religioso. Esto quiere decir, que la cultura como exclusiva creación del hombre, sería puesta en duda, por muchas culturas y civilizaciones, ajenas a la tradición secularista moderna de occidente. Como reconociera Paul Ricoeur, en un abordaje que salvaguarda de manera benevolente, a diferencia del marxismo, la noción de ideología que maneja el antropólogo C. Geertz, se debe reconocer la actividad creativa del hombre, como dinámica y transformadora de culturas (Ricoeur, 2008, p. 275). Es importante hacer valer los contenidos propios de cada cultura y reconocer la autocomprensión mítica de sus propios portadores como expresiones ideológicas con profundos contenidos ontológicos Hay que superar en la lectura de los universos símbolicos la noción marxista de falsa conciencia que termina condicionando e imponiendo lecturas tecnoambientales y tecnoeconómicas que ignoran y no reconocen el valor del pensamiento y prácticas sociales discursivas en las perspectivas invertidas que se mantienen aun en el conocimiento de los pueblos de la Tierra.

\section{Cierres y aperturas}

Quizás uno de los resultados más importantes de la reflexión epistemológica en ciencias sociales, en relación con el llamado giro lingüístico, sea el de postular que el hombre actúa en una red de significados simbólicos autónomos o relativamente autónomos, orientados a dominar un mundo que a su vez tiene que ser conocido en el funcionamiento de sus lógicas de vida. La acción del hombre siempre está lingüísticamente mediada, posición teorética surgida gracias a la filosofía analítica del lenguaje, la lingưística y la semiótica (Wittgenstein, 1988, 2003; Saussure, 1994; Peirce, 1986).

En conclusión, la historia y epistemología de las ciencias sociales, son campos axiales para adentrarnos en los significados que se suceden en los terrenos del mundo de la cultura y en el mundo del sujeto humano, condición que impone la imperiosa necesidad del diálogo disciplinar, interdisciplinar y transdisciplinar. Al mismo tiempo, se reconoce la importancia del diálogo intercultural, como vía para lograr el descentramiento de la lógica de la ganancia y la rentabilidad, que en 
su apetito voraz viene paradójicamente descodificando (destruyendo) y codificando (alienando) aceleradamente el mundo de la vida. De ahí que existan significados (conceptos) y significantes (imágenes materiales) que no se corresponden con los valores de la libertad, sabiduría, bondad, justicia, poder noético, imaginación, verdad y razón que deben estar en la base societaria de cualquier estado social de derecho contemporáneo que de manera honesta se planteara un diálogo con los mejores principios de la tradición universal de la raza humana. Estos principios deben de orientar la investigación científica, superando el mero naturalismo descriptivo que se satisface con sus representaciones del mundo real. La empresa científica, debe apuntar a señalar, con el mayor rigor posible, el deber ser de la realidad, mandato ilustrado y base de la filosofía moral de las ciencias sociales.

La inteligencia científica debe de estar en capacidad de impulsar los modos de pensamiento sobre esferas incluso incognoscibles, pero no absolutamente incomunicables, destacando los signos de la experiencia y de la razón (Peirce, 1973). Esta condición de ser vivida, puede reconstituir el "cosmos sagrado" frente a los paisajes monoculturales del neoliberalismo multinacional, y de los fanatismos políticos y religiosos de toda índole que siguen dominando la trama histórica de la humanidad.

\section{Referencias bibliográficas}

Apel, K.O. (1997). El camino del pensamiento de Charles S. Peirce. Madrid: Visor.

Asad, T. (1973). "Introduction" En: Talal Asad (ed.), Anthropology and the Colonial Encounter. Atlantic Highlands: Humanities Press. Pp. 1-19.

Bachelard, G. (1986). La Formation de l'esprit scientifique. Paris: J. Vrin.

Barthes, R. (1993). La aventura semiológica. Buenos Aires: Paidós. 
Bauman, Z. (2002). La hermenéutica y las ciencias sociales. Buenos Aires: Nueva Visión.

Bourdieu, P. y Wacquant, L. (2008). Una invitación a la sociología reflexiva. Buenos Aires: Siglo XXI.

Boudon, R. y Bourricaud, F. (1982). Dictionnaire critique de la sociologie. Paris: PUF.

Bulgakov, S. (2012). Unfading Light. Contemplations and Speculations. Grand Rapids, Michigan/ Cambridge, U.K.: William B. Eerdmans Publishing Company.

Cárdenas, F. (2016). El signo paisaje cultural desde los horizontes de la antropología semiótica. En. Aibr. Revista de Antropología Iberoamericana. Volumen 11 Número 1, Enero - Abril, Pp. 105 - 129.

Cassirer, E. (1983). Antropología filosófica. Madrid: FCE.

Coomaraswamy, A. (1980). El Tiempo y la eternidad. Madrid: Taurus.

Corbin, H. (1996). Cuerpo espiritual y tierra celeste: del Irán mazdeíta al Irán chiíta. Madrid: Edidiciones Sirvela.

Courtés, Joseph. (1997). Análisis semiótico del discurso. Del enunciado a la enunciación, Madrid: Gredos.

Dilthey, W.(1980). Introducción a las ciencias del espíritu: ensayo de una fundamentación del estudio de la sociedad y de la historia. Madrid: Alianza Editorial.

Durand, G. (1982). Las estructuras antropológicas de lo Imaginario: introducción a la arqueotipología general. Madrid: Taurus.

Durkheim, E. (1964). Las reglas del método sociológico. Buenos Aires: Dédalo.

Durkheim, E (2004). El suicidio. Buenos Aires: Libertador.

Elias, N. (2006). Sociología fundamental.Barcelona: Gedisa Editorial.

Eliade, M. (1989). Imágenes y símbolos. Ensayos sobre el simbolismo mágico-religioso. Madrid: Taurus.

Foucault, M. (1995). "Qué es la crítica? En Daimon, Revista de Filosofía, Murcia, No 11.

Foucault, M. "Qué es la ilustración", Copia mimeo.

Gadamer, H. G. (1993). Verdad y método I. Salamanca: Sígueme.

Garza Toledo de la, E.; Leyva, G. (eds.) 2012. Tratado de metodología de las ciencias sociales: perspectivas actuales. México, D.F: Universidad Autónoma Metropolitana-Fondo de Cultura Económica.

Geertz, C. (1973). The Interpretation of Cultures. New York: Basic Books.

Girard, R. (1986). The Scapegoat. Baltimore: Johns Hopkins University Press. 
Guenón, R. (1988). La crisis del mundo moderno. Barcelona: Obelisco. Harris, M. (1968). El desarrollo de la teoría antropológica. Madrid: Siglo $\mathrm{XXI}$.

Hottois, G. (1997). Historia de la filosofía del renacimiento a la posmodernidad. Madrid: Cátedra.

Kertzer, D. (2009). Social Science History, Duke University Press: Social Science History Association, 33:1.

Lansing, J.S. y Downey, S. (2011). Complexity and Anthropology. Philosophy of Complex Systems. London: Elsevier.

Latour, B. (2011). Politics of Nature: East and West perspectives, Ethics and Global Politics. Descargado de http://www.brunolatour.fr/poparticles/poparticle/P-154-DELHI-EGP.pdf

Lévi-Strauss, C. (2006). Antropología estructural: Mito, sociedad, humanidades. México: Ediciones Siglo XXI.

Lossky, V. (1982). Teología mística de la iglesia de oriente. Barcelona: Herder.

Luhmann, N. (1998). Sistemas sociales. Barcelona: Anthropos.

Marx, K. (2012). Obra selecta: Antología de textos de economía y de filosofía; Manuscritos de París; Manifiesto del partido comunista; Crítica del programa de Gotha. Edición Jacobo Muñoz. Cartoné. Biblioteca de Grandes Pensadores. Madrid: Editorial Gredos.

Macintyre, A. (2001). Tras la virtud. Barcelona: Crítica.

Mancilla, H.C.F. (2017). El postmodernismo, los estudios postcoloniales y la aproximación a la verdad en las ciencias sociales. Nómadas. Revista Crítica de Ciencias Sociales y Jurídicas. Vol. 52, no.4.

Mendelssohn, M. (2014). Acerca de la pregunta. ¿̇A qué se llama ilustrar? Descargado de http://filosofiaieslaorden.wikispaces.com/file/view/MOSSES\%20MELDELSS ONN.pdf/418060928/MOSSES\%20MELDELSSONN.pdf

Monares, A. (2003) Calvinismo, ilustración y Ciencias Sociales: Providencia absoluta, negación del libre albedrío y leyes de la conducta. Revista Persona y Sociedad. Vol. 17, No. 1.

Saussure, F. (1994). Curso de lingüística general. Buenos Aires: PlanetaAgostini.

Sayer, A. 2004. Restoring the Moral Dimension: Acknowledging Lay Normativity. Published by the Department of Sociology: Lancaster University, Lancaster LA1 4YL, UK. Descargado de http://www.lancaster.ac.uk/fass/sociology/papers/sayer-restoring-moraldimension.pdf

Sciacca, M.F. (1960). La Filosofía Hoy. Barcelona: Editorial Luis Miracle. 
Scheff, T. (2011). The Catastrophe of Scientism in Social/Behavioral Science. Contemporary Sociology. Vol. 40, No. 3.(May), pp. 264-268.

Sorokin, P. (1969). Sociedad, cultura y personalidad. Madrid: Aguila.

Sorokin, P. (1957). Achaques y manías de la sociología moderna y ciencias afines. Madrid, Aguilar.

Trigo, A. (2008). Las humanidades en la encrucijada de la globalización. Revista de Crítica Literaria Latinoamericana. Año XXXIV, No. 68, LimaHanover NH, Segundo, pp. 33-53.

Ordóñez Díaz, L. (2006). La formulación del principio de inmanencia en el fragmento de Anaximandro. Tópicos, Revista de Filosofía. México: Universidad Panamericana, pp. 81-121.

Orozco, A. (1977). La libertad en el pensamiento. Madrid: Ed. Rialp.

Pannenberg, W. (1993). Antropología en perspectiva teológica. Salamanca: Ediciones Sígueme.

Peirce, C. (1973). La ciencia de la semiótica. Buenos Aires: Ediciones Nueva Visión. Descargado de http://es.scribd.com/doc/93427602/Peirce-La-ciencia-de-la-semiotica

Peirce, C. (1986). La ciencia de la semiótica. Ediciones Nueva Visión: Buenos Aires.

Parsons, T. (1976). El sistema social. Madrid: Revista Occidente.

Rappaport, R. (2001). Ritual y religión en la formación de la humanidad. Madrid: Cambridge.

Viveiros, E. (2010). Metafísicas caníbales. Líneas de Antropología Postestructural. Buenos Aires: Katz Editorial.

Velasco, A. (2012). Hermenéutica y ciencias sociales. En: Garza Toledo de la, E.; Leyva, G. (Eds.) Tratado de metodología de las ciencias sociales: perspectivas actuales. México, D.F: Universidad Autónoma Metropolitana-Fondo de Cultura Económica.

Voegelin, E. (1952). The New Science of Politics: An Introduction. Chicago: University of Chicago Press.

Wolf, E. (2005). Europa y la gente sin historia. Buenos Aires: Fondo de Cultura Económica. 